\title{
La Filosofía de Keynes o The common sense view of economic world
}

\author{
MANUEL MONTALVO \\ Universidad de Granada
}

\begin{abstract}
RESUMEN. El objeto de este artículo es analizar la relación existente entre las ideas de Keynes y de Moore; y en particular, el papel desempeñado por el sentido común en el pensamiento de aquél. Fruto de este análisis, cabe afirmar que el sentido común ofrece una posible fundamentación epistemológica para el pensamiento económico, cuya virtud principal es que incrementaría el contenido pragmático de la teorización económica. El argumento se centra, principalmente, en el problema de la formación de expectativas y en el hecho de que, en consonancia con la visión filosófica de Keynes, se precisan normas acordes con el sentido común para paliar la naturaleza irracional e incierta de los hechos económicos.
\end{abstract}

\begin{abstract}
This paper's aim is to examine the relation between Keynes' ideas and Moore's ones. Particularly, the analysis will be focused on the role played by common sense in Keynes' thought. As a result of this analysis, the paper argues that common sense provides a possible epistemological foundation for economic thought, whose main virtue is that it would increase the pragmatic content of economic theorisation. The argument is mainly centred on the problem of expectation forming, and on the fact that, in tune with Keynes' philosophical view, norms based on common sense are needed in order to mitigate the irrational and uncertain nature of economic phenomena.
\end{abstract}

Sobre el sentido común se ha dicho de todo, no todo: todo es una palabra sobre la que pesa la penosa y agustiniana significación de lo irrellenable, de lo que es imposible ocupar a no ser que fuera con otro y misterioso imposible.

Huyendo de los extremos, sólo sea por fidelidad a lo que se trata de decir, hay que dejar fuera que el sentido común sea una suma de vulgaridades, y también, un excelso instrumento que atribuyera razón a todas las cosas. Más bien sería todo lo que el mundo sabe, aquello que compromete a creencias y opiniones más o menos fundadas y mezcladas con errores y prejuicios. $\mathrm{Y}$ que se refiere a una presunta actividad mental espontánea del hombre para conocer los aspectos fundamentales de la realidad; primeramente, la existencia de las cosas y nuestra propia existencia, y en segundo lugar, lo que surge inmediatamente de la propia evidencia. Siguiendo a Thomas Reid y a la 
Escuela Escocesa se podría decir que el sentido común está relacionado con un instinto o especial sentimiento de búsqueda de la verdad. Y para lo que aquí se refiere, son éstos los antecedentes que permiten incluir a Moore y a Keynes en una rama de pensamiento que ha tenido un respetable predicamento entre los filósofos ingleses 1 .

Para acotar la cuestión y evitar estériles compromisos, interesa la noción que tiene Moore del sentido común, que, al decir de Muguerza ${ }^{2}$, y como se sugiere en «What is Philosophy?» ${ }^{3}$, se encuentra mejor en la filosofía especulativa que en la llamada analítica. De acuerdo con el entendimiento mooreano del sentido común, se da como cierta la existencia de cosas materiales y de actos de consciencia. Bastará agregar, además, que estas cosas están relacionadas en el espacio y el tiempo para deducir también la existencia de los mismos, del espacio y el tiempo. De esta cima se pueden descender una serie de «... trivialidades cuya "verdad" creo conocer con toda certeza. [...] En el momento presente hay un cuerpo humano vivo que es el mío. Este cuerpo ha nacido en una época pasada y desde entonces ha existido con continuidad [...]. Al nacer (y algún tiempo después) era mucho más peque$\tilde{n} o$ de lo que es ahora» ${ }^{4}$. Con estas certezas, Moore se arroga la licencia de afirmar que «... la "Visión del mundo del Sentido Común" es completamente verdadera en ciertos aspectos fundamentales» 5 .

Llama la atención que la propiedad con que afirma la verdad del sentido común Moore se repita insistentemente en las páginas de la Teoría general de la ocupación, el interés y el dinero ${ }^{6}$, una obra que aparentemente no

1 Vid. F. Comim, «The Scottish Tradition in Economics and the Role of Common Sense in Adam Smith's Thought», Review of Political Economy, núm. 14, 2002, pp. 91-114.

2 J. Muguerza, «Del sentido común al lenguaje común: el lugar de G. E. Moore en la filosofía contemporánea», en G. E. Moore, Defensa del sentido común y otros ensayos, Madrid, Taurus, ( $1 .^{a}$ ed. en inglés: 1925), 1972, pp. 18 ss.

${ }^{3}$ G. E. Moore, «What is Philosophy?», en G. E. Moore, Some Main Problems of Philosophy, Londres, Allen \& Urbin, 1969.

${ }^{4}$ G. E. Moore, op. cit., 1972, p. 58.

5 «... soy uno de aquellos que han sostenido que la Visión del mundo del Sentido Común es completamente verdadera en ciertos aspectos fundamentales. Pero hay que recordar que, según mi punto de vista, todos los filósofos sin excepción han coincidido con esta tesis mía; y que la diferencia real, que se expresa comúnmente de este modo, se establece solamente entre aquellos filósofos que han mantenido también puntos de vista incompatibles con estos aspectos de la visión del mundo del Sentido Común y los que no lo han hecho».

«Los aspectos en cuestión (...) tienen esta propiedad particular; a saber, que si sabemos que son aspectos de la Visión del mundo del Sentido Común, se sigue de ello que son verdaderos: es autocontradictorio mantener que nosotros sabemos que son aspectos del punto de vista del Sentido Común y que, sin embargo, no son verdaderos, puesto que decir nosotros conocemos esto es decir que son verdaderos», ibid., pp. 70-71.

6 J. M. Keynes, The General Theory of Employment, Interest and Money, vol. VII, The Collected Writings of John Maynard Keynes, Londres, MacMillan Press, 1989 (1936), edición de D. E. Moggridge y E. Johnson. La influencia filosófica de Moore sobre Keynes es mucho más nítida y está más presente que la de Wittgenstein. Esta no se contiene de manera explícita, y constituye otra fuente de estudio de la que aquí no se hace cuestión ni objeto. Al respecto, vid. J. Coates, 
debiera tener relación alguna con las especulaciones filosóficas; pero a poco que se repare en ella se encontrará una defensa del sentido común aplicado a algunas trivialidades económicas cuya verdad Keynes cree conocer con toda certeza.

\section{II}

Se ha intentado buscar el puente que debía de unir las concepciones filosóficas de Keynes con sus discurrimientos económicos y, en especial, con la Teoría General, pero se ha seguido una vía falsa. Sobre todo cuando se ha tomado como referente las primeras incursiones de Keynes en la filosofía, que se hallaron dirigidas hacia los terrenos estéticos ${ }^{7}$. Bajo la influencia de Burke y, en especial, de Moore, se ocupó en ellas de la belleza en sí y de la verdad y del bien como belleza ${ }^{8}$. Preocupaciones bastante lejanas de la prosaica realidad que es la economía, y que se han de entender dentro del marco cultural de la sociedad victoriana, cuya imagen nos trae la Mrs. Dalloway de Virginia Woolf, tan atenta a comprar flores que llenen los jarrones de los salones de su casa para que siempre sea primavera y pueda evadirse de las confusiones y dudas que la rodean y afligen. Eran ya tiempos difíciles para la estética: el mal gusto de las conversaciones políticas y de los gritos obreros empezaba a empañar la serenidad en la que parecía reflejarse la sociedad. También eran malos para la ética: de lo que se trata es de cambiar el mundo, y no parecía que el modo adecuado de hacerlo fuera continuar interpretándolo como no era $\mathrm{o}$, si se quiere, como no se presentaba en la realidad de principios del siglo XX.

Frente a lo que se ha creído, tampoco se desbrozaba el camino para llegar a la Teoría General partiendo de los Principia Ethica de Moore. Esta creencia ha sido imbuida por el propio Keynes en «My Early Beliefs», un texto de importancia menor que en ciertos pasajes se convierte en un ejercicio de exculpación de las influencias mooreanas. En él, con interés de peregrino arrepentido, echa la vista atrás Keynes para seguir confesando una admiración comprensible, ya sin ninguna inocencia, por los Principia Ethica ${ }^{9}$, pero

The Claims of Common Sense: Moore, Wittgenstein, Keynes and the Social Sciences, Cambridge, Cambridge University Press, 1996.

7 Vid. R. O'Donnell, «Keynes on Aesthetics», History of Political Economy, supl. del vol. 27, New Perspectives on Keynes, 1995, pp. 96 ss.

${ }^{8}$ Beauty, Miscellanea Ethica, Theory of Beauty, Melodramas, Henry or Rupert y Science and Art son las obras que pertenecen a esta primera época.

9 «Fui a Cambridge el día de San Miguel de 1902, y los Principia Ehtica de Moore aparecieron al final de mi primer año. Nunca he escuchado que aquella generación los hubiera leído. Pero, obviamente, su efecto sobre nosotros, y las discusiones que precedieron y siguieron a su publicación, lo dominó todo $-\mathrm{y}$ tal vez continúa dominándolo - [...]. Sólo para nosotros, aquellos que éramos activos en 1903, la influencia de Moore completamente desplazó a McTaggart, Dickinson, o Russell. La influencia (...) fue excitante, estimulante, el comienzo de un renacimiento, la apertura de un nuevo cielo en una nueva tierra. Éramos los pioneros de una nueva bendición, no estábamos asustados de nada.» J. M. Keynes, «My Early Beliefs», en Essays in Biography, vol. X de The 
que, a esas alturas, no podía seguir siendo la misma: la sociedad había cambiado, sus intereses también, y había escrito la Teoría General, «...que revolucionará en buena parte - supongo que no de inmediato, pero sí en el transcurrir de los próximos diez años- el modo en que el mundo piensa acerca de los problemas económicos» ${ }^{10}$. Así fue, así ha seguido básicamente siendo, y no, precisamente, a través de la senda marcada en los Principia de Moore, que sólo le valen a Keynes para justificar y valorar con la desmesura del recuerdo de los tiempos felices la heterodoxia compartida con el grupo de Bloomsbury. Aquellos excesos que no fueron aprobados por Russell ${ }^{11}$. No obstante, alguna ventaja le rindió la devoción mooreana: su pensamiento arribó a una especie de juego sin consecuencias, ni reglas de conducta, ni acciones, que le permitía escapar del cálculo hedonista y del credo del marxismo, al que consideraba la reductio ad absurdum del benthamismo ${ }^{12}$.

La abyección a Marx y al marxismo la conservó siempre ${ }^{13}$. En cambio, aquel juego sin compromisos desapareció cuando hubo de enfrentarse a las cuestiones económicas, donde lo más importante son las consecuencias que

Collected Writings of John Maynard Keynes, Londres, MacMillan Press, edición de D. E. Moggridge y E. Johnson, 1989 [1938], p. 435.

10 Citado por R. Skidelsky, John Maynard Keynes. The Economist as Saviour, 1920-1937, Londres, MacMillan Press, 1992, pp. 520-521.

11 «... la generación de Keynes y Lytton [...] se proponía [...] una vida de retiro entre finas sombras y delicados sentimientos, y concibieron que lo bueno consistía en la apasionada y mutua admiración entre los miembros de una camarilla de élite. Esta doctrina, de manera bastante injusta, se la atribuyeron a Moore, del que se preciaban ser discípulos. Keynes, en sus memorias, Early Belifs (sic), ha manifestado por la doctrina de Moore su admiración. Moore dio el debido peso a la moral y, mediante su doctrina de las unidades orgánicas, evitó el punto de vista de que el bien consiste en una serie de apasionados momentos aislados; pero aquellos que se consideraron a sí mismos sus discípulos ignoraron este aspecto de su enseñanza y degradaron su ética hasta convertirla en el sentimentalismo irrespirable de una escuela de señoritas». B. Russell, The Autobiography, Londres, Allen \& Unwin, 1967-1969, p. 184.

12 «Vivíamos en el presente engañoso, y tampoco habíamos empezado a jugar el juego de las consecuencias. Existíamos en el mundo de los Diálogos de Platón; no habíamos alcanzado la República, por no decir las Leyes.»

«Esto nos dio una gran ventaja. Como habíamos arrojado al hedonismo por la ventana (...), y vivíamos completamente en la experiencia del presente; desde el momento en que habíamos dejado fuera de nuestro Ideal a la acción social como un fín en sí mismo, y no meramente como un lúgubre deber, y no sólo a la acción social, sino a la vida de acción en general - es decir, al poder, la política, el éxito, la riqueza, la ambición-, concediendo menos preeminencia al motivo económico y al criterio económico en nuestra filosofía que San Francisco de Asís [...]; se seguía, de todo ello, que estábamos entre los primeros de nuestra generación, quizá los únicos de nuestra generación, que escapamos de la tradición benthamita.» J. M. Keynes, op. cit., 1989 (1938), p. 445.

${ }_{13} \ll$ Mis sentimientos acerca de Das Kapital son los mismos que me inspira El Corán. Sé que es importante históricamente y sé que mucha gente, de la que no todos son idiotas, lo considera como una especie de piedra filosofal y lo encuentra plagado de genialidades. Sin embargo, cuando miro en su interior, me parece inexplicable que pueda tener este efecto. Es pesado, está desfasado [...]. Pero, entonces, siento exactamente lo mismo por El Corán. ¿Cómo puede cualquiera de estos libros sembrar el fuego y la espada por medio mundo?» Citado por R. Skidelsky, op. cit., 1992, p. 520. 
se siguen de la conducta de los individuos. Pero, por ciertas razones y también por esnobismo, Keynes quiso aparecer como una especie de inmoral: Sigo siendo, y seguiré siéndolo siempre, un inmoral ${ }^{14}$. En «My Early Beliefs» esboza la silueta de un inconformista que no está interesado en absoluto en la ética de la conducta de los individuos, rechaza de plano toda responsabilidad personal en la obediencia de normas generales y se rebela contra la moral fundada en la costumbre, las convenciones y el saber imperante. Es una forma de rebeldía que elegantemente se mantiene a la altura de la vacuidad; pero cuando esa inmoralidad tiene que convertirse en hechos, en actitudes razonadas y, lo más importante, en consecuencias, debe ser analizada. ¿Qué es una conducta moral, y qué no? De acuerdo con los patrones culturales de la época, la moral implica previsión, cálculo, frugalidad, sacrificio, renuncia. Y lo inmoral, lo contrario: imprevisión, indolencia, prodigalidad, exceso. Pero esto no es más que una mera serie de contrarios que nada dice.

Hagamos uso del sentido común y establezcamos alguna clase de medida para conocer hasta qué punto lo moral es moral; lo inmoral, inmoral; o lo inmoral, moral, y a la inversa. Una medida puede ser la pobreza, o la riqueza, o lo que conjuga a las dos: la facilidad para vivir ante la limitación que imponen unos recursos económicos escasos. De inmediato se podrá deducir que las conductas morales son dañinas, provocan estancamiento económico y depauperación, porque se mueven en el terreno de las falacias: ¿Lo bueno para uno es bueno para todos? Ciertamente una conducta acordada a la previsión, el cálculo, la frugalidad y la espera es buena para el individuo; pero no así cuando el uno se convierte en el todos: si todos los individuos deciden ser previsores, ordenados y frugales el resultado no puede ser más que catastrófico. Esto es algo que se sabe, forma parte del conjunto de creencias precientíficas que se integran en ese gran acervo de conocimiento que es el sentido común. Ya lo había dicho Bernard MandeviIle, del que Keynes hace cita de autoridad en la Teoría General: ;Vicios privados, virtudes públicas!

Y antes de Mandeville lo había dicho Martínez de Mata en el siglo XVII: Con lo que unos gastan demasiado, otros comen lo necesario, que es como una especie de adagio erasmista o quizá sólo sea un refrán común, requerido de una llana explicación: ¿Qué suerte sería la de una sociedad en la que todos los individuos decidiesen ser frugales y honrados, dejaran de beber, de comer con exceso, de vestir con lujo, de procrear por placer? Perecería: una sociedad virtuosa es una sociedad que adelanta su extinción. Bastante en lo cierto estaba Mandeville al loar el panal rumoroso, la sociedad que hace del vicio el manantial de la riqueza. La prostituta con sus veleidades permite que trabajen y coman las costureras, y el pródigo, que lo hagan criados,

${ }_{14}$ J. M. Keynes, op. cit., 1989 (1938), p. 447. 
cocheros, vinateros, cosecheros... Esto es fácil de comprender, tanto como puede serlo entender un vulgar refrán.

La labor de Keynes va a consistir en elaborar una teoría de cierta sofisticación sobre este conocimiento ingenuo. Pero antes tendrá que romper con el idealismo, incluido el idealismo de Moore de los Principia Ethica: «El Nuevo Testamento es un manual para los políticos en comparación con el idealismo del capítulo [de los Principia Ethica] de Moore acerca de "The Ideal". No he conocido igual en la literatura desde Platón. Y es mejor que Platón, porque está bastante más libre de "fantasía". Expresa la belleza de la habilidad literaria de la mente de Moore, la pura y apasionada intensidad de su visión, desnuda y real [...] Moore tuvo una vez una pesadilla en la que no podía distinguir las proposiciones de las mesas. Pero incluso cuando estaba despierto, no podía distinguir el amor, la belleza y la verdad de un mueble. Aquéllas se hallaban igual de definidas que éste, adquirían las mismas cualidades estables, sólidas y objetivas, y la misma realidad de sentido común» 15 .

Realidad de sentido común, de eso se trata, de acabar con las ideas de progreso moral continuo de la humanidad, de racionalidad y de verdad, que tan sólidamente asentadas estaban que el propio Keynes, en aquellos albores del siglo $\mathrm{XX}$, tomaba como cierto que los individuos, determinados por la ley del progreso moral, eran responsables, honrados, racionales y objetivos, y que su conducta estaba motivada por la búsqueda de la verdad. Evidentemente, estos felices supuestos y realidades imposibles no son un comienzo para conocer qué sucede en el presente inmediato y quizá por qué. Los individuos son todo lo contrario: ni responsables, ni racionales, ni objetivos, y se debe entender que la sociedad sobrevive mediante el establecimiento de un conjunto de normas que limitan la irracionalidad al nivel que no pone en peligro la reproducción social. Keynes ha advertido su error ${ }^{16}$ y lo rectifica en la Teoría General, de modo que sustituye la racionalidad inexistente por la irracionalidad real. Es como si se hubiera dicho: vamos a razonar, empiécese por inquirir sobre la naturaleza humana: ¿cómo es? Para responder hay

\footnotetext{
is Ibid., p. 444

16 «En síntesis, rechazábamos todas las versiones del pecado original, de que hubiera manantiales de maldad insanos e irracionales en la mayoría de los hombres. No nos dábamos cuenta de que la civilización era una costra delgada y precaria erigida por la personalidad y el deseo de unos pocos, y tan sólo mantenida por las normas y convenciones hábilmente comunicadas y astutamente preservadas. No tuvimos respeto por la sabiduría tradicional, ni por el peso de la costumbre [...]. No respetamos el logro extraordinario de nuestros predecesores en la organización de la vida (como ahora me parece que ha sido) o el marco elaborado que ellos han ideado para proteger este orden (...). Como causa y consecuencia de nuestro estado mental general no comprendimos en absoluto la naturaleza humana, incluyendo la nuestra. La racionalidad que le atribuimos a esta naturaleza condujo a la superficialidad, no sólo de juicio, sino también de sentimiento. [...] Habíamos perdido, sin reemplazarlo, algo que nuestros predecesores tuvieron. Sigo sufriendo incurablemente por atribuir una racionalidad irreal a los sentimientos y al comportamiento de otra gente (y sin duda, también a los míos propios).» Ibid., p. 448.
} 
que tomar a los individuos tales como son y analizar las acciones a que les impulsan sus sentimientos, que no son necesariamente buenos, ni calculados, ni previsores. Pueden ser malos, dañinos y no obedecer a ningún patrón reflexivo: nacen obligados por la euforia o la tristeza. Depositar alguna clase de confianza en los impulsos surgidos de la emotividad y creer que siguen unas pautas racionales artífices del tejido que forman las relaciones sociales es poco sensato y tiene mucho de empobrecedor ${ }^{17}$, o con palabras del mismo Keynes, se trata de un desastroso error. Por tanto, procede rectificar: los individuos requieren de la existencia de normas generales de conducta ${ }^{18}$, cuyo establecimiento supera la idea de simple resumen de experiencias contenidas en el concepto de probabilidad frecuencial ${ }^{19}$; y yendo a mayores, no sólo han de entenderse las normas como superación, sino como rechazo de la idea de probabilidad. De la mayor o menor probabilidad de un hecho no se sigue el establecimiento de una norma. Dicho sea esto sin que sirva de adelanto de conclusiones, porque la oposición de Keynes a la probabilidad frecuencial, y también a la probabilidad subjetiva, se produce en el ámbito de $A$ Treatise on Probability ${ }^{20}$, un estudio que no conduce a mejores puertos, ni tampoco anticipa la Teoría General.

\section{III}

A título de comienzo sobre el estudio de lo probable, dice Keynes de forma aforística que la probabilidad es la propia guía de la vida, para seguidamente establecer lo que no es; no son frecuencias, ni sucesos recurrentes, sino que se relaciona con los estados cognitivos y mentales implicados en los argumentos lógicos con los que se formula. Luego, la probabilidad es un juicio lógico.

17 «Me parece, ahora, que la atribución de racionalidad a la naturaleza humana, en lugar de enriquecerla, la empobrece, puesto que implica ignorar ciertas fuentes de sentimiento poderosas y valiosas. Algunos de los arrebatos espontáneos e irracionales de la naturaleza humana pueden tener un tipo de valor del que nuestro esquematismo fue aislado. Incluso algunos de los sentimientos que surgen de la maldad pueden tener valor. Y junto con los valores que surgen de los impulsos espontáneos, volcánicos e, incluso, malvados, hay muchos otros objetivos de contemplación y comunión valiosos más allá de los que conocemos [...]. Uno debe recordar siempre el dictum de Paley de que [...] nada realmente existe 0 , siente sino los individuos; sin embargo, llevamos demasiado lejos el individualismo de nuestros individuos.» Ibid., pp. 447-448.

18 Vid. Y. Shionoya, «Sidgwick, Moore and Keynes: A Philosophical Analysis of Keynes' "My Early Beliefs"», en B. W. Bateman y J. B. Davis (eds.), Keynes and Philosophy. Essays on the Origin of Keynes' Thought, Brookfield, Edward Elgar, 1991, pp. 6-29.

19 Vid. J. B. Davis, «The Rules of the Road», en B. W. Bateman y J. B. Davis (eds.), op. cit., 1991, pp. 55-68, y J. B. Davis, «Keynes' Later Philosophy», History of Political Economy, supl. del vol. 27, New Perspectives on Keynes, 1995, p. 245.

20 J. M. Keynes, A Treatise on Probability, vol. VIII, The Collected Writings of John Maynard Keynes, Londres, MacMillan Press, edición de D. E. Moggridge y E. Johnson, 1988 (1921). 
Con este principio asienta el concepto de probabilidad en una posición clásica, pero añade una diferencia, la que marca el concepto de conocimiento, que no es ilimitadamente amplio y cuya validez no está sostenida sobre la verdad. El conocimiento es limitado, es sólo un cierto conocimiento, el máximo que puede ser obtenido. De aquí que la probabilidad no esté relacionada con el conocimiento en un sentido amplio; más bien, lo está con ese cierto conocimiento derivado del empleo de argumentos, que no tienen por qué ser subjetivos ni implicar que la probabilidad lo sea, pues la probabilidad es objetiva al estar relacionada con un grado de creencia que es tomado como racional ${ }^{21}$.

El fin de $A$ Treatise on Probability es extender la lógica a todas las formas de conocimiento, que una visión reducida o demasiado ortodoxa de la investigación científica había excluido. Hay que aplicar la lógica a toda clase de creencias, opiniones, al conocimiento limitado, a lo cierto, a lo probable e, incluso, a la incertidumbre. ¿Y qué es para Keynes lo cierto, y qué lo probable? Depende de las creencias, del distinto grado de creencia racional que se le otorgue a las proposiciones. El mayor o menor conocimiento que se tenga de una proposición determinará su certeza o probabilidad. A su vez, el conocimiento se relaciona con las circunstancias, de modo que estas surgen como limitaciones. Una proposición podrá ser igualmente falsa o cierta dependiendo del conocimiento con que se relaciona la proposición ${ }^{22}$.

Entre verdad y probabilidad no hay una relación directa. La probabilidad comienza y termina en la misma probabilidad. Por mucho que sea el conocimiento probable que se tenga de una proposición, ello no habilita para concluir que sea cierta. No se podrá hacer ecuación entre certeza y verdad: los grados de certeza sobre una proposición no son iguales a sus grados de verdad, como tampoco la racionalidad es equivalente a la verdad. Se puede racionalmente creer que una proposición es falsa y, al mismo tiempo, mantener una creencia irracional de que es verdadera.

21 «... en el sentido relevante para la lógica, la probabilidad no es subjetiva; es decir, no se halla sujeta al capricho humano. Una proposición no es probable porque pensemos que lo es. Una vez que los hechos que determinan nuestro conocimiento se hallan dados, lo que es probable o improbable en estas circunstancias ha sido fijado objetivamente, $y$ es independiente de nuestra opinión. La teoría de la probabilidad, por tanto, es lógica, porque se ocupa del grado de creencia que es racional mantener en condiciones dadas, y no meramente de las creencias reales de individuos particulares, que pueden o no ser racionales». Ibid., p. 4.

22 «Los términos cierto y probable describen los distintos grados de creencia racional que sobre una proposición nos autorizan a albergar diferentes cantidades de conocimiento. Todas las proposiciones son ciertas o falsas, pero el conocimiento que de ellas tenemos depende de nuestras circunstancias; y aunque a menudo resulte conveniente hablar de las proposiciones en términos de su certeza o probabilidad, lo que esto estrictamente expresa es una relación de dichas proposiciones con un corpus de conocimiento, real o hipotético, y no una característica de las proposiciones en sí mismas. Al mismo tiempo, esta relación puede ser mayor o menor para una misma proposición, en función del conocimiento con el que se halla relacionada; de tal modo que no tiene relevancia alguna llamar a una proposición probable a menos que especifiquemos el conocimiento con el que la relacionamos.» Ibid., pp. 3-4. 
La idea de probabilidad de Keynes sigue muy de cerca el concepto de verdad de Moore: se trata de una noción no simple, no analizable, indefinible, no natural, directamente percibida o intuida y objetiva, y al igual que Moore escribió que cada cosa es lo que es y no puede ser otra cosa, la probabilidad para Keynes es lo que es y no otra cosa. Incluso llega a afirmar lo siguiente: «Una "definición" de la probabilidad no es posible [...]. No podemos analizar la relación de probabilidad en términos de ideas más simples» ${ }^{23}$.

Una vez establecido que la probabilidad está relacionada con cierto grado de racionalidad, parece que tuviera un carácter cuantitativo, responsable de que pueda ser objeto de medida. Sin embargo, no es así; y no lo es por mucho que las teorías de la probabilidad ampliamente aceptadas concuerden su definición con su naturaleza numérica, con la afirmación de que la probabilidad no puede ser sino un número. Semejante conclusión que no es compartida por Keynes por dos razones. Primero, porque el aumento de ejemplos positivos de un experimento no aumenta la probabilidad, y segundo, porque en muchos casos es absurdo asignar a la probabilidad un valor numérico. Así, se puede decir que un hecho es más probable que otro porque se ha dado en un número mayor de ocasiones, pero no que es el doble o el triple más probable.

Fiel a los Principia Ethica de Moore, Keynes, en A Treatise on Probability busca el lado fácil del problema de la conducta de los individuos, aquel que la relaciona con la probabilidad y con el lema de Butler: Para nosotros, la probabilidad es la propia guía de la vida. De ser así, lo desconocido que se oculta a cualquier acción o conducta sería todavía no conocido, pero no imposible de conocer, y las acciones se tomarían siguiendo el metro de lo probable, sin que la ignorancia sea un obstáculo insuperable. La ignorancia no puede ser óbice para hacer una afirmación en relación con la probabilidad, puesto que, aun cuando la probabilidad implica ignorancia, no hay necesidad de convertirla en imposibilidad ${ }^{24}$.

La probabilidad es un eficaz paliativo de la incompletitud y limitaciones del conocimiento. De poseerse un conocimiento completo, la probabilidad carecería de sentido. Y por ser el conocimiento limitado, la intuición es básica para elaborar juicios de probabilidad. El proceso intuitivo es objetivo y contrario a la experiencia, provee una razón para mantener que una proposición es cierta, siempre que no sea evidente por sí misma, cuando en realidad no hay razones que revelen su verdad.

Estas aseveraciones siguen el patrón de pensamiento mooreano, en donde la inducción es un proceso lógico que no depende en absoluto del éxito de las predicciones. La validez y naturaleza razonable de la inducción es una cuestión de lógica y no de experiencia, de leyes formales y no materiales.

23 Ibid., p. 8.

24 Vid. ibid, p. 341. 
No hará falta mucho detenimiento para concluir que la teoría de la probabilidad keynesiana carece de sentido, como Ramsey, con claridad, puso en evidencia ${ }^{25}$. Primero, porque mezcla los argumentos factuales con los lógicos, y segundo, porque, si bien se pueden inferir conclusiones factuales de premisas factuales, no se puede afirmar que la conclusión sea lógicamente necesaria. Si el propósito de Keynes fue lograr alguna clase de respaldo para un argumento incierto, un argumento sostenido por un conocimiento que no puede ser obtenido directamente, falló en su propósito ${ }^{26}$, pues de poco les vale a dos individuos la teoría de la probabilidad keynesiana cuando, aun compartiendo la misma evidencia, tengan distinta opinión sobre la ocurrencia de un suceso ${ }^{27}$.

Los errores cometidos por Keynes cabe achacarlos a los Principia Ethica, que le habían inducido a situar la ética en el concepto indefinible de bien, y la razón práctica, en la probabilidad. Los tiempos hicieron mudanza, y después de la Primera Guerra Mundial nada puede seguir igual: ha surgido una nueva visión de las cosas, lo probable no es una hipótesis racional, la probabilidad no es tan sólo un juicio lógico, tampoco es un proceso lógico la inducción, ni la intuición es objetiva.

Todos estos cambios se van a hacer presentes en la Teoría General. El mundo probable y racional de $A$ Treatise on Probability se convierte en un mundo sin probabilidades, incierto, que hace de cualquier conducta una conducta necesariamente irracional. Irracionalidad e incertidumbre se han convertido en dos categorías históricas que conllevan una nueva forma de pensar. La única conducta posible - llamarla racional no sería apropiado bajo las condiciones de incertidumbre reflejadas en la Teoría General - sería

25 Ramsey niega que haya «... cosas tales como las relaciones de probabilidad que él (Keynes) describe. Keynes supone que, en ciertos casos al menos, tales relaciones pueden ser percibidas; pero, en lo que a mí respecta, estoy seguro de que esto no es así. No las percibo, y si se pretende persuadirme de que existen, habrá de ser mediante argumentos; es más, sagazmente sospecho que otras personas tampoco las perciben, porque apenas si son capaces de alcanzar un mínimo acuerdo acerca de cuál es la relación de probabilidad que vincula dos proposiciones dadas». F. Ramsey, The Foundations of Mathematics and Other Logical Essays, Londres, Routlege and Kegan Paul, 1978 (1925), pp. 192-193.

26 Vid. E. H. Jr. Kyburg, «Keynes as a Philosopher», History of Political Economy, supl. del vol. 27, New Perspectives on Keynes, 1995, p. 11.

27 De acuerdo con el teorema de Finetti, bajo ciertas circunstancias, las opiniones de dos individuos convergen cuando aumenta la evidencia de un suceso. Este mismo fenómeno de convergencia es aplicado a las expectativas epistémicas para mostrar que dos individuos que no compartan los mismos valores cognitivos pueden esperar la convergencia hacia la aceptación de las mismas teorías cuando la evidencia se acumula. Al respecto, vid. P. Maher, Betting on Theories, Cambridge, Cambridge University Press, 1993. 
cumplir con el deber de uno consigo mismo sin que importaran las consecuencias. La razón práctica no está fundada en la lógica de la probabilidad, sino en una lógica del deber, en una ética de motivos carente de todo consecuencialismo ${ }^{28}$.

Con el atributo de racionalidad otorgado a los individuos y la negativa a aceptar la relevancia de las normas y convenciones acuñadas en el saber tradicional, Keynes había ido demasiado lejos, como propiamente reconoce en «My Early Beliefs»; pero aún era más erróneo no considerar la incertidumbre como un hecho que entra a formar parte de todas las conductas. Por esto, puede ser conveniente plantear la existencia de alguna clase de racionalidad débil $\mathrm{o}$, dicho más exactamente, de una serie de normas que a espaldas de su origen y validez científica permitan cierta eficacia en el funcionamiento de la sociedad. Esto no es que quede claro; sólo se percibe, como es normal que suceda en un pensamiento tan poco sistemático como el keynesiano. Decir más, decir que hay una declaración implícita sobre la necesidad de normas y convenciones es una prótesis inútil ${ }^{29}$. Más bien, se va deduciendo conforme se desarrollan las proposiciones económicas con un lenguaje que ya no requiere de la precisión de los Principia, sino que es ambiguo, se halla plagado de lugares comunes y menos precisado de otras razones que no sean razones vulgares. Acierta Skidelsky cuando dice que «... la economía era un juego que él (Keynes) podía jugar, un lenguaje que podía usar, una poderosa herramienta de pensamiento; pero las fuentes de comprensión de la vida económica estaban fuera o debajo de su propia y característica forma de pensar» ${ }^{30}$, que es - aunque no lo advierta Skidelsky - mooreana, y lo va a seguir siendo, con la importante salvedad de que se ha desplazado a the common sense view of world ${ }^{31}$, alzada ante el vacuo idealismo en que ha sido sumido el análisis de las relaciones económicas; porque seguramente el conocimiento económico, para que sea conocimiento, requiera de sentido común, de que alguien afirme Tengo la certeza de que estoy de pie o de que estoy sentado cuando se está sentado o se está de pie. Claro que se podrá decir, en perjuicio de Moore, que se da por demostrado lo que se quiere demostrar; pero nadie podrá negar que decir en economía Tengo la certeza de que estoy de pie es una valiosa determinación en un farragoso idealismo como el económico. Y no es que Keynes fuera el primero en recurrir al sentido común. Los filósofos escoceses habían hecho un uso profuso de él, incluyendo al propio Adam Smith, quien afirmó que «... no es la benevolencia del panadero, del cervecero o del carnicero la que nos procura el alimento, sino la consideración de su propio interés». Es decir, por su egoísmo, ¿y hay

28 Vid. A. Fitzgibbons, «The Significance of Keynes’ Idealism», en B. W. Bateman y J. B. Davis (eds.), op. cit., 1991, pp. 126-132.

29 Vid. A. Carabelli, On Keynes' Method, Londres, The MacMillan Press, 1988, pp. 148-150.

30 Vid. R. Skidelsky, op. cit., 1992, p. XIX.

${ }^{31}$ La concepción del mundo basada en el sentido común. 
algo más grosero y vulgar que el egoísmo?, ¿hay algo que sea más de sentido común?

En realidad, los más sólidos razonamientos económicos son juiciosos y vulgares. Tanto lo son que se convierten en verdades de perogrullo; como sucede con las argumentaciones de Malthus sobre la insuficiencia del consumo, asumido por Keynes como una especie de evangelio de la realidad económica que levantaba contra Ricardo y sus abstractas demostraciones de equilibrio en un demasiado y lejano futuro, tan lejano que se diría inexistente: A largo plazo, todos muertos. Así, nos encontramos ante dos visiones económicas del mundo. Una, surgida del sentido común, llana y vulgar en la medida en que no es filosófica. La otra, de naturaleza idealista, hace abstracción de las cosas y se evade de las coordenadas de espacio y tiempo reales; tanto se evade que, por este no tener los pies en el suelo, tildó Keynes a Ricardo de ser para la economía la Inquisición española.

Pensando que una pregunta pudiera ser primeramente una respuesta, un problema sería previamente una solución. Cuando no hay solución tampoco hay problema. Ésta es la forma de entender lo económico de la economía liberal, para la que las relaciones económicas carecen de otro fin que no sea la resolución de un equilibrio a través de la oferta y la demanda con plena flexibilidad de precios. Ciertamente podría surgir un exceso de oferta o de insuficiencia de demanda, pero sería meramente circunstancial y transitorio, sin que en nada pueda comprometer el equilibrio con pleno empleo de los recursos económicos. Y no existirían inconvenientes mayores para admitir que en un plano ideal fuese así, salvo que descendiendo de lo ideal se cayera de bruces en el problema, que no es una perturbación pasajera, y que delata que es la solución del problema, precisamente, el problema. Con lo que aparece un dilema: ¿Se cambia la realidad o se niega la solución del problema? Lo más acordado con el sentido común es cambiar la solución del problema, buscar otra solución para el problema surgido: revelado en que el pleno empleo es una quimera, y la flexibilidad de precios, un fantasma apabullado por una sociedad sumergida en las constantes políticas y culturales de su siglo. ¿Se puede conceder que los precios y salarios son flexibles después de la irrupción de las masas en la historia y de que hayan conquistado una parte del poder político en los parlamentos?

La solución propuesta por Keynes reside en la acumulación de capital y en el progreso técnico; sin embargo, llegar a alcanzar esta solución no es fácil: hay que remover pesados obstáculos. El primero es el idealismo económico, en mucho parecido a una especie de hegelianismo que niega el 
tiempo para llegar a tener una idea de lo real; algo que en absoluto difiere de rechazar la realidad económica para lograr una idea de su realidad.

Uno de los presupuestos del idealismo económico es el principio de laissez faire, que no es ciertamente un principio económico: es un principio político que hizo posible la oportunidad de separar la sociedad civil del Estado mediante la afirmación de que una sociedad de individuos que trabajen, compren y vendan con plena libertad puede sobrevivir por sí misma, y siempre que no medie la intervención del Estado. Bastaba para que obrara el singular prodigio el que se asegurara la libertad natural de los hombres para competir en el mercado.

Para valorar en su justo término el principio de laissez faire, Keynes convierte a los hombres en jirafas con plena libertad natural para luchar por el vivir: «No cuenta el coste de la lucha, sino sólo los beneficios del resultado final, que se suponen permanentes. Siendo el objeto de la vida cortar las hojas de las ramas hasta la mayor altura posible, la manera más plausible de alcanzar este fin es permitir que las jirafas con el cuello más largo dejen morir de hambre a las que lo tienen más corto. [...] Así, si dejamos que las jirafas se comporten libremente, [...] más y más jugosas hojas serán engullidas, y cada hoja alcanzará la garganta que considera que ha acreditado un mayor esfuerzo [...]. Si nos preocupa el bienestar de las jirafas, no debemos pasar por alto los sufrimientos de las de cuellos más cortos, que están muertas de hambre, o las dulces hojas que caen al suelo y son pisoteadas en la lucha, o el hartazgo de las que tienen el cuello largo, o el mal aspecto de ansiedad o voracidad agresiva que nubla los pacíficos rostros del rebaño» ${ }^{32}$.

El ingenuo darwinismo no se sostiene ni siquiera metafóricamente: no es posible que haya suficientes hojas para alimentar a las jirafas, a no ser que fuera en una fábula de Esopo con la que se pretendiera ensalzar alguna cualidad moral. No es el caso. Dentro de los límites de la sensatez es de esperar que la situación de equilibrio con pleno empleo sea una situación extrema dentro de todas las posiciones de equilibrio. Lo normal, lo que sucede con regularidad y generalidad, es que el paro esté siempre presente en el funcionamiento económico, y no por otra condición que la necesaria para su funcionamiento. Claro, si se me permite cierto abuso con las jirafas, se podría admitir que existe una situación de pleno empleo cuando el paro sea voluntario, concepto que hay que tomar como una rareza de las muchas que tuvo Pigou, y que convierte a algunas jirafas en voluntarias aspirantes a morirse de hambre; y eso sí, sería lo peor, sin la espera de la santidad que no es asunto de esta especie. Definitivamente, según Keynes, el paro es involuntario y consecuencia de la insuficiente demanda agregada.

32 J. M. Keynes, «The End of Laissez-Faire», en Essays in Persuasion, vol. IX, The Collected Writings of John Maynard Keynes, Londres, MacMillan Press, edición de D. E. Moggridge y E. Johnson, 1984 (1926), pp. 282-284. 
De nuevo recurramos a Moore: Tengo la certeza de que estoy de pie, que es la certeza de Keynes cuando se enfrenta - como él llama a los economistas liberales- a los teóricos clásicos, que «... se asemejan a los geómetras euclidianos en un mundo no euclidiano, quienes, al descubrir que en la realidad las líneas aparentemente paralelas se encuentran con frecuencia, las reprenden por no mantenerse derechas - como único remedio ante las desafortunadas colisiones que están teniendo lugar-. No obstante, en verdad, no hay más remedio que tirar por la borda el axioma de las paralelas y elaborar una geometría no euclidiana. [...] Necesitamos [...] elaborar la teoría del comportamiento de un sistema en el que el paro involuntario, en un sentido estricto, sea posible» ${ }^{33}$.

Para situarse en un mundo no euclidiano había que rechazar la Ley de Say ${ }^{34}$, una proposición carente de sentido empírico, que no es sino una tautología de la clase $A \equiv A$, y que se enuncia así: Toda oferta crea su propia demanda, viniendo a establecer que en los elementos de oferta se hallan siempre presentes los elementos de demanda: en el precio de los sombreros se hallan incluidos los ingresos que facilitan que los individuos se cubran con respetables sombreros. La posibilidad de que no se cumpla la igualdad tautológica entre oferta y demanda es contenida en los términos de excepcionalidad pasajera, porque, si en un período extraordinario la oferta fuese mayor que la demanda, $O>D$, los precios bajarían, dando lugar a un aumento de la demanda y a una disminución de la oferta que restablecerían el equilibrio; y en caso contrario, el equilibrio se alcanzaría a través de una subida de los precios.

Este feliz equilibrio negaba, como hubiera hecho un filósofo avant la letre, que la mano derecha fuese la mano derecha de Moore, y la izquierda, la izquierda, no sólo porque lo dijera, sino también porque las levantaba a modo de prueba irrefutable, tan irrefutable como las colas de parados, los cierres de fábricas y las dificultades de abastecimiento. Hechos palpables y contables, tanto como las dos manos de Moore, y que ponían en evidencia la

\footnotetext{
33 J. M. Keynes, op. cit., 1989 (1936), p. 17.

34 «Desde los tiempos de Say y Ricardo los economistas clásicos han enseñado que la oferta crea su propia demanda - queriendo señalar con esto, aunque sin definirlo claramente, que el total de los costes de producción debe necesariamente gastarse por completo, directa o indirectamente, en comprar los productos [...]. Sin embargo, quienes piensan de este modo se engañan, como resultado de una ilusión óptica, que hace que dos actividades esencialmente diversas aparezcan como iguales. Caen en una falacia al suponer que existe un eslabón que liga las decisiones de abstenerse del consumo presente con las que proveen al consumo futuro, cuando los motivos que determinan las segundas no se relacionan en forma simple con los que determinan las primeras.»

«Por tanto, el supuesto de igualdad entre el precio de demanda y el de oferta de la producción total es el que debe considerarse como el axioma de las paralelas de la teoría clásica. Y admitido este axioma, todo lo demás se deduce fácilmente - las ventajas sociales de la frugalidad privada o nacional, la actitud tradicional hacia la tasa de interés, la teoría clásica de la desocupación, la teoría cuantitativa del dinero, las ventajas evidentes del laissez faire con respecto al comercio exterior y muchas otras cosas que habremos de poner en tela de juicio-is Ibid., pp. 18-21.
} 
desigualdad radical entre oferta y demanda: la demanda era crónicamente insuficiente. Históricamente siempre fue así: los pobres, los trabajadores, carecían de poder de compra o adquisitivo para adquirir los bienes. Algo que estaba fuera de dudas, como denunció Sismondi y repitió con fidelidad plagiaria Malthus.

Como es muy común en los pensadores ingleses, debe de ser culpa de la dolencia o pecado de insularidad, Keynes no tomó en cuenta ningún antecedente teórico sobre la insuficiencia de la demanda o el subconsumo, excepto el de Malthus y, casi en secreto, el de Gesell y el Major Douglas. Aunque tenía conocimiento de que las crisis de subconsumo habían recibido un extenso tratamiento en la teoría marxista, por autores como Rosa Luxembourg, Hilferding o Bauer, despreciaba dicho análisis por un prurito de buen gusto, que no terminaba de disimular el horror que sentía al comunismo, de cuya llegada sería culpable la teoría clásica ${ }^{35}$.

A espaldas de todo idealismo, el remedio a la insuficiencia de demanda o subconsumo no exigía de mucha discusión: aumentar el consumo, que, para insistir en lo obvio, y parafraseando a Keynes, es el único objeto y fin de la actividad económica, puesto que las oportunidades de ocupación sólo pueden derivarse del consumo presente o de las reservas para el consumo futuro.

Urgía pasar de una sociedad fundada sobre las virtudes del ahorro a otra basada sobre los pecados del consumo. Se trataba de sustituir la parafernalia ptolomeica sobre el ahorro, compleja y banal, por la rotundidad copernicana del consumo, ya en un mundo que había dejado de ser ptolomeico. Había que hacer sencillo e inmediato aquello que efectivamente lo es. La mediatez del ahorro, la postergación de sus fines al futuro compensador y distante, es incompatible con la perentoriedad del presente, carente de esperas y recompensas más allá de la pura inmediatez. El presente es el consumo que es preciso aumentar a través de la elevación de la renta de los individuos menos favorecidos. Algo que sólo está al alcance del Estado, que no es la falacia del mal necesario, sino su contrario: el bien necesario, y como todo bien hay que aumentarlo, porque de sus acciones depende una mejor distribución de la renta que a la vez eleva el consumo y evita el derrumbamiento de la sociedad.

35 «Los marxistas se han convertido en economistas ultra-ortodoxos. Se valen del argumento ricardiano para mostrar que nada puede lograrse a través del intervencionismo. Así, dado que las cosas van mal y no existe remedio posible, la única solución es abolir [el capitalismo] y tener un sistema totalmente nuevo. El comunismo es el resultado lógico de la teoría clásica.» Citado por R. Skidelsky, op. cit., 1992, p. 511. 
Lo dicho es sumamente claro, simple y juicioso, es de sentido común; aunque no case con las ideas sobre el ahorro, cuya bondad hace ecuación con su permanencia en el tiempo. Hay que ser frugales, condenar los dispendios, guardar para el mañana, son mandamientos del buen vivir para seguir viviendo tras la muerte. La inmortalidad se convierte en un negocio de ahorro y acumulación para el ahorrador, transformado por Keynes en un criador de gatos: «No ama a su gato, sino a los gatitos de su gato; ni tampoco, en realidad, a los gatitos, sino tan sólo a los gatitos de los gatitos, y así sucesivamente, hasta el fin, en el reino de los gatos. Para él, la mermelada no es mermelada, a menos que se trate de mermelada mañana y nunca de mermelada hoy. De esta manera, siempre empujando a su mermelada hacia el futuro, se esfuerza por asegurar para su acto de cocerla una inmortalidad» ${ }^{36}$.

Ciertamente no se compadecen bien la elevada e idílica inmortalidad con el terrenal cocimiento de la mermelada; pero, la verdad sea dicha, es que de la primera no vive el hombre, y sí de la segunda.

Si el culto a la inmortalidad quedara apartado a los lares de la intrascendencia, no sería caso de mayores reparos. No sería asunto de mayor detenimiento, si acaso para la mística. Pero la cuestión estriba en que no es así, en que la conducta del rentista carece de una justificación razonable y es merecedora para Keynes de una grave sanción, la eutanasia. El argumento de la inexorable sentencia descansa sobre la aparente existencia de un pacto social: cada uno de los individuos está comprometido en la realización de una función social objetivada en un provecho concreto, medible en términos de riqueza y valorable en dinero. En contrapartida, la sociedad remunera al individuo con una especie de renta o ingreso. La función social que cumple el individuo es aportar trabajo, o puede derivarse de la propiedad de un bien que introduce en el proceso productivo; pero ¿es acaso el dinero una propiedad escasa?, ¿está sometida su multiplicación a alguna especie de limitación física o natural? La tierra está limitada por una frontera natural insalvable: tierra hay la que hay, y si se demanda más es lógico que el precio de arrendamiento o renta aumente ante la inapelabilidad de la ley de los rendimientos decrecientes. Así no ocurre con el capital, una propiedad artificialmente escasa que degenera en unas tasas de interés injustificables o de razón no justificable, porque a medida que los tipos de interés son más elevados la inversión es más baja, más penoso su aumento.

La droga económica para acabar con la agonía rentista está al alcance de la mano: basta aumentar la cantidad de capital, romper con las limitaciones artificiales y hacerlo abundante. Una facultad del Estado derivada de su vo-

36 J. M. Keynes, «Economic Possibilities of Our Grandchildren», en Essays in Persuasion, op. cit., 1984 (1930), p. 330. 
luntad de poder. $\mathrm{Al}$ aumentar la cantidad de dinero, bajarían los tipos de interés y su propiedad se haría menos valiosa o económicamente más estéril ${ }^{37}$.

\section{VII}

No puede haber nada espurio en una conclusión tan liviana. Las ideas económicas acostumbran a responder, cuando no se ocupan de vaciedades expresadas en un lenguaje complejo, a unos patrones de suma sencillez. La gravedad de las ideas económicas está en sus consecuencias, de las que difícilmente los individuos pueden evadirse: «...tanto cuando son correctas como cuando están equivocadas, son más poderosas de lo que comúnmente se cree» ${ }^{38}$.

Efectivamente, en un mundo de intereses, en un mundo que es preciso vivir todos los días de una vida y de todas las vidas, son las ideas económicas las que imponen la senda que se seguirá. Si equivocada, equivocada; si acertada, acertada. En ambos casos, es fruto de un cúmulo de circunstancias inabarcables para cualquier lógica. Lo que sucede, muy confusa y complejamente, sucede, y no cabe situarse más que en este ámbito, dejando de lado toda clase de tiempos subjuntivos y ubicaciones ideales. Ya es suficiente con decir Tengo la certeza de que estoy de pie, y si acaso, agregar: ... en un casino, que no es un capricho ingenuo: es el lugar más parecido al sistema económico, en el que el individuo más o menos se badea con su irracionalidad.

Como ocurre en el mercado, en un casino se hacen envites, se aceptan, se rechazan o se sobreponen apuestas, se gana o se pierde. De continuo se especula con ganar levantando una carta, bajando la palanca de una máquina o empujando una ruleta. Los que ganan justifican su ganancia mediante un lo sabía. Los que pierden lo achacan a la mala suerte, que tampoco aclara mucho más. Sólo queda el hecho en sí, lo que se gana o se pierde en las apuestas. Muy parecido a lo que se gana o se pierde comprando o vendiendo

37 «... este estado de cosas [...] significaría la eutanasia del rentista y, en consecuencia, la del poder de opresión acumulativo del capitalista para explotar el valor de escasez del capital. Hoy el interés no recompensa de ningún sacrificio genuino, como tampoco lo hace la renta de la tierra. El propietario del capital puede obtener interés porque el capital es escaso, lo mismo que el dueño de la tierra puede percibir renta debido a que la tierra es escasa. Pero, mientras que puede haber razones intrínsecas para la escasez de la tierra, no existen razones intrínsecas para la del capital». J. M. Keynes, op. cit., 1989 (1936), pp. 375-376.

38 «En realidad, el mundo está gobernado por poco más que eso. Los hombres prácticos, que se creen exentos por completo de cualquier influencia intelectual, son generalmente esclavos de algún economista difunto. Los maniáticos de la autoridad, que oyen voces en el aire, destilan su frenesí inspirados en algún escritorzuelo académico de hace algunos años. Estoy seguro de que el poder de los intereses creados es grandemente exagerado en comparación con la invasión gradual de las ideas, que, en la práctica, no sucede de forma inmediata, sino después de un cierto intervalo [...]. Pero, tarde o temprano, son las ideas, y no los intereses creados, quienes resultan peligrosas, tanto para mal como para bien.» Ibid., pp. 383-384. 
en los mercados, siempre con la fe puesta en unas eventuales ganancias. A los individuos que se arriesgan a comprar y vender en pos de una ganancia se les atribuye que tienen espíritu de empresa, término muy difícil de deslindar de la más real especulación. El ejemplo más llamativo se encuentra en las bolsas de valores, que, definidas como mercados de capitales, tendrían que servir para canalizar el ahorro de los particulares hacia las sociedades mercantiles que realizan la función inversora.

Haciendo bueno a Moore se diría que esto es un disparate, y puesto en boca de una persona lega en estos asuntos, obligaría de inmediato a corregirle como se hace con un niño que toma las sillas por fantasmas: Éstas son sillas y sirven para sentarse. Qué duda cabe de que afirmado por un economista se le añade sorprendentemente una gratuita verosimilitud. Carece de ninguna. Las bolsas de valores no tienen como fin financiar las inversiones; sólo tienen una función especuladora: se compra para vender o se vende para comprar de nuevo, para obtener un precio remunerador ${ }^{39}$. Con gran fidelidad esto es lo que sucede en el sistema capitalista en su conjunto: las conductas económicas obedecen a una especulación sobre los rendimientos futuros. En este sentido, no hay diferencia entre el inversor y el especulador. Ninguno de ellos realiza previsiones a largo plazo sobre las ganancias probables que generará una inversión en el tiempo de su duración. Su atención está dirigida a prever los cambios que puedan registrarse en las bases de valoración para anticiparse a los demás individuos. No invierten para siempre: esto sería un error. Lo hacen para cuando sea oportuno vender, que puede ser ahora, inmediatamente o inmediatamente más tarde, nunca demasiado tarde, dependiendo del clima económico, que no se sabe bien qué es, salvo que es aparentemente paradójico: cuando los resultados económicos son halagüeños, se eleva el índice de crecimiento económico, disminuye el paro y la inflación está contenida, sorprendentemente las compras menguan; y al revés, los datos negativos inducen a grandes adquisiciones. Sin embargo, no hay nada paradójico: los especuladores interpretan los sucesos de acuerdo con su particular rasero y sin un atisbo de objetividad.

Dos apuntes más sobre la irracionalidad. Primero, las conductas irracionales marcan la trayectoria que sigue el proceso de inversiones. La conducta global de los inversores, una especie de promedio, determina qué va a ocu-

39 «Si se me permite aplicar el término especulación a la actividad de prever la psicología del mercado, y el de empresa a la tarea de prever los rendimientos futuros que generarán los activos durante todo su período de vida, [...] a medida que mejora la organización de los mercados de inversión, el riesgo de que la especulación predomine aumenta. [...] Los especuladores pueden no hacer daño cuando sólo son burbujas en una corriente firme de espíritu de empresa. Pero la situación es seria cuando la empresa se convierte en burbuja dentro de una vorágine de especulación. Cuando el desarrollo del capital de un país se convierte en subproducto de las actividades propias de un casino, es probable que aquél se realice mal [...]. Generalmente existe acuerdo en que, por interés público, los casinos deben ser inaccesibles y costosos, y tal vez esto mismo sea cierto en el caso de las bolsas de valores.»Ibid., pp. 158-159. 
rrir en el futuro. Será vender o será comprar, depende de los estados mentales, que en absoluto están relacionados con los estados mentales de Moore: son mucho más prosaicos y están en consonancia con las ganancias esperadas. Segundo, establecida la irracionalidad como referente de la conducta económica, la racionalidad no es posible al estar en contra de las pautas generales.

La fuente de la irracionalidad con que funciona el mercado se encuentra para Keynes en la naturaleza humana: «... una gran parte de nuestras actividades positivas depende más del optimismo espontáneo que de una expectativa matemática, ya sea moral, hedonista o económica. Probablemente, la mayor parte de nuestras decisiones de hacer algo positivo, cuyas consecuencias completas se irán presentando en muchos días por venir, sólo pueden considerarse como resultado de la fogosidad - de un impulso espontáneo hacia la acción en lugar de a la inacción-, y no como consecuencia de un promedio ponderado de los beneficios cuantitativos multiplicados por las probabilidades cuantitativas» ${ }^{40}$, que, de tener unas bases consistentes para realizar su cálculo, serían menos relevantes que el capricho, el sentimentalismo o el azar.

Lo que haya de ser el devenir económico, mejor o peor, y por más que importe a los individuos, se rige por la aleatoriedad, que tan pronto se torna en una ola de pesimismo como en una ola de optimismo. Las situaciones halagüeñas dan paso a predicciones negativas: aumentará el paro, los precios crecerán, la renta disminuirá, sin que haya ningún motivo razonable para que las cifras del futuro sean peores que las del presente. ¿Qué sucede? Lo único que se alcanza a decir es que la predicción adelanta un sentimiento de malestar, de que las cosas van a peor, de agotamiento que finalmente se convierte en que las cosas están mal.

\section{VIII}

Abandonado por imposible el mundo de las probabilidades, la Teoría Gene$\mathrm{ral}$ se enfrenta a un futuro desconocido por incierto. No hay forma de construir un puente que una el presente con el futuro. Pudo ser la probabilidad, que une lo conocido con lo probable; pero no lo es, porque la incertidumbre es causa de que la probabilidad lo sea de un hecho imposible, cuyo valor no puede ser más que cero. Sin embargo, es necesario construir el futuro, sin que sea asunto de mayores vuelos cómo se haga, ya que tan irracional es dejar de hacerlo como hacerlo a través de una conducta irracional; aunque pese más esta segunda opción por el impulso humano de vivir. Luego, es una necesidad elaborar el futuro. Lo que sea después, un error o un acierto,

\footnotetext{
40 Ibid., p. 161.
} 
ya está fuera de la satisfacción de esa urgencia con que se enfrenta el individuo.

Para elaborar ese devenir se hace preciso recurrir al sentido común, a lo que se hace por lo común, y que consiste en suponer que los acontecimientos futuros se van a presentar ciertamente como se espera. Es la forma de formular las expectativas, disponiendo de un grado de certeza que carece de cualquier base racional, pero que satisface la necesidad de creer que el futuro será como se piensa. Para ello se apartan todos los hechos inciertos, dejan de tenerse en cuenta, y se toman aquellos que inspiran confianza, los cuales no pueden ser más que los del presente conocido y extrapolado hacia el futuro ${ }^{41}$.

Después, conforme se vayan presentando los hechos, las expectativas se van modificando para adaptarse a las nuevas situaciones. Se convierten en expectativas adaptativas, que, aun careciendo de rigor científico, permiten ir sorteando la cenagosa imposibilidad de la incertidumbre, que debe considerarse como natural. Lo natural tiene el significado de sumisión y conformidad, en el sentido más fiel de la frase de Esquilo: La fuerza del destino es inevitable.

La incertidumbre que puede ser calificada de económica tiene su origen en el mercado y no puede disociarse de su funcionamiento. La formación de los precios es un proceso azaroso sobre el que no cabe establecer ninguna regla, y es causa de que en el juego de tontos y listos que se realiza en el mercado a los listos les favorezca la incertidumbre e ignorancia en perjuicio de los tontos, quienes han de soportar las desigualdades de renta y el paro inherentes al mercado.

Dada la incertidumbre y la irracionalidad de los sujetos, no parece que pueda establecerse dilema alguno entre razón privada y razón pública, y ello por un motivo fuera de discusión: la razón privada no existe. Otra cuestión es que de su existencia se haga un auto de fe.

Sólo queda la razón pública, que es también operativa y se concreta en una ordenación de medios y fines. Los medios se contienen en la política económica. Los fines son el empleo, la distribución de la renta y su crecimiento. Y como los medios son posibles y los fines alcanzables, la razón es consistente.

Bajo estos auspicios, ya es posible construir una teoría económica sobre un realismo conceptual organizado en un cuerpo de relaciones de dependencia funcional entre los diferentes agregados económicos: consumo, inver-

41 «Al plantear nuestras expectativas sería una estupidez atribuir gran influencia a motivos que sean muy inciertos. Por tanto, es razonable dejarse guiar principalmente por los hechos que nos inspiran cierta confianza, aunque tengan una importancia menos decisiva para nuestros fines que otros respecto de los cuales nuestro conocimiento es vago y escaso. Por este motivo, los hechos presentes forman parte - en cierto sentido, desproporcionadamente- del proceso de formación de nuestras expectativas a largo plazo. Nuestra costumbre es tomar la situación actual y proyectarla en el futuro, modificándola tan sólo en la medida en que tengamos motivos más o menos definidos para esperar una variación.» 
sión, renta, grado de distribución, gasto público, impuestos..., y de aquí, un conjunto de normas y convenciones carentes de visos de cientificidad, pero que establecen un marco de racionalidad en el que queda inscrito el funcionamiento del mercado y un cierto y posible equilibrio de la sociedad.

\section{IX}

Para terminar, sirva un lugar común. Se podrá decir que la visión del mundo económico de Keynes es tan falsa como la afirmación de que la Tierra es plana, pero sucede que, hasta que no se demuestre que el mundo económico es redondo, lo más juicioso y atinado es seguir pensando que es plano y que debajo de nosotros los árboles no crecen al revés. Al fin y al cabo, a lo que sí que no se asemeja la realidad económica es a un mundo euclidiano de curvas perfectas que se entrecruzan sobre un punto al que platónicamente denominamos equilibrio, y que poco tiene que ver con la irracionalidad que sustancia la conducta de los individuos, la incertidumbre determinante de las decisiones, la involuntariedad del paro y la dinámica errática e impredecible del mercado. Sobre este marasmo, lo más acordado es proyectar la visión del sentido común, que viene a hacer de premisas para los argumentos económicos, los cuales, finalmente, concluyen en la formulación de normas económicas, de discutible validez científica, pero capaces de sostener el mundo económico, aunque sea de manera tambaleante, sobre el plano de una muy controvertida realidad.

Ésta es la filosofía de Keynes, sólo y especulativamente sentido común. 